\title{
Endoscopic exchange of a lumen-apposing metal stent after endoscopic ultrasound- guided gastroenterostomy in severe acute pancreatitis
}

Endoscopic ultrasound-guided gastroenterostomy (EUS-GE) has been an effective and safe alternative to surgery for the palliation of symptoms of gastric outlet obstruction (GOO) due to benign or malignant conditions [1-3]. The lumenapposing metal stent (LAMS) is a necessary device for EUS-GE because of its anti-migration role and long-term patency [4]. However, there is no clear in vivo evidence of the duration of LAMS efficacy. There is still no evidence on when the LAMS should be exchanged especially when used in benign GOO. We report a case of endoscopic exchange of LAMS after EUS-GE in severe acute pancreatitis. A 49-year-old man experienced severe acute pancreatitis after excessive alcohol intake. Although his condition greatly improved with active treatment, he pre- sented 3 months later with progressive nausea, vomiting, and poor oral food intake. Upper gastrointestinal imaging (UGI) and gastroscopy revealed duodenal obstruction due to distortion of the descending part of the duodenum. A nasojujunal feeding tube was implanted deeply beyond the ligament of Treitz and exchanged every 3 months. However, the symptoms had not improved
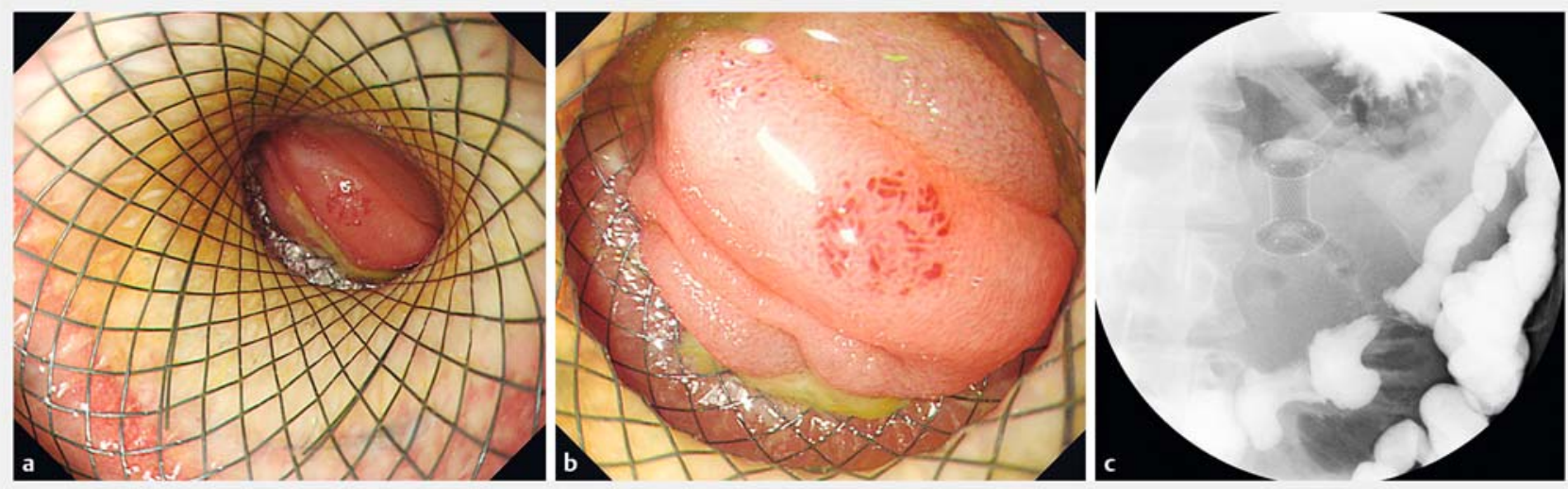

- Fig. 1 Endoscopic ultrasound-guided gastroenterostomy with a lumen-apposing metal stent. a Gastroscopy showed that the stent had expanded well 2 days after the procedure. $\mathbf{b}$ Gastroscopy showed the mucosa of the jejunum clearly through the stent. c Fluoroscopy showed that the stent had expanded well.
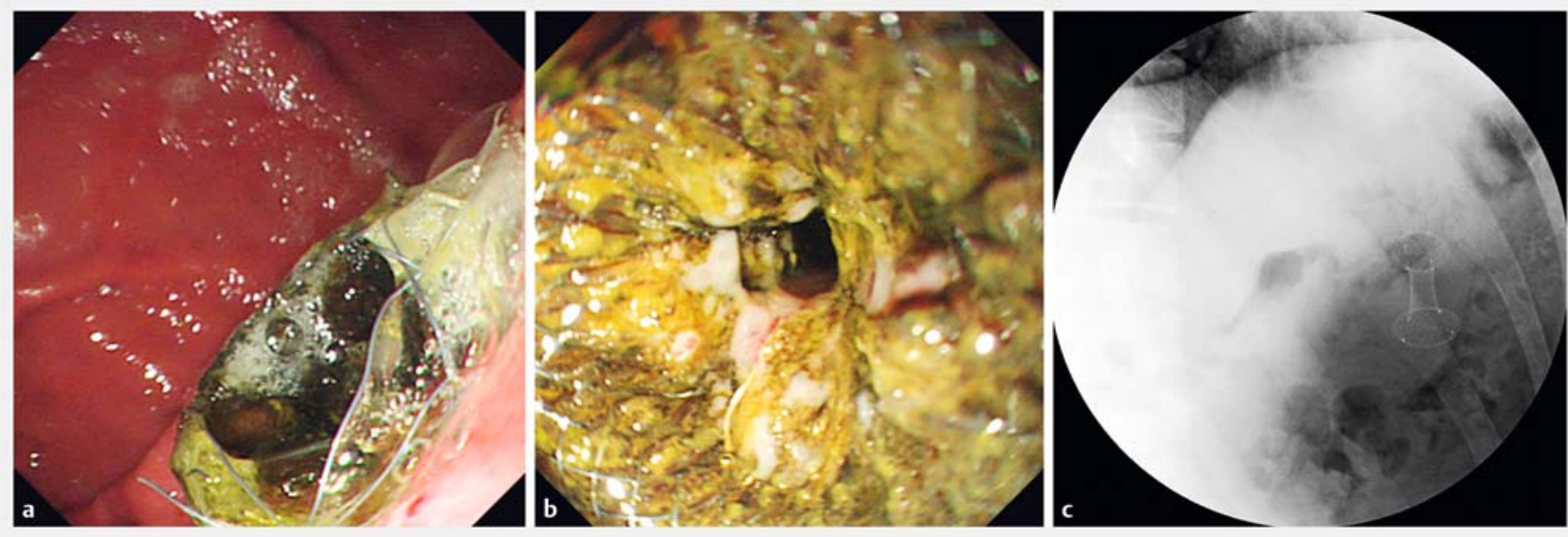

Fig. 2 The stent became ineffective due to corrosion by gastric juice. a Gastroscopy found fractures in some of the steel wires of the stent. b, $\mathbf{c}$ Gastroscopy and fluoroscopy showed that the inner diameter of the stent had decreased significantly. 


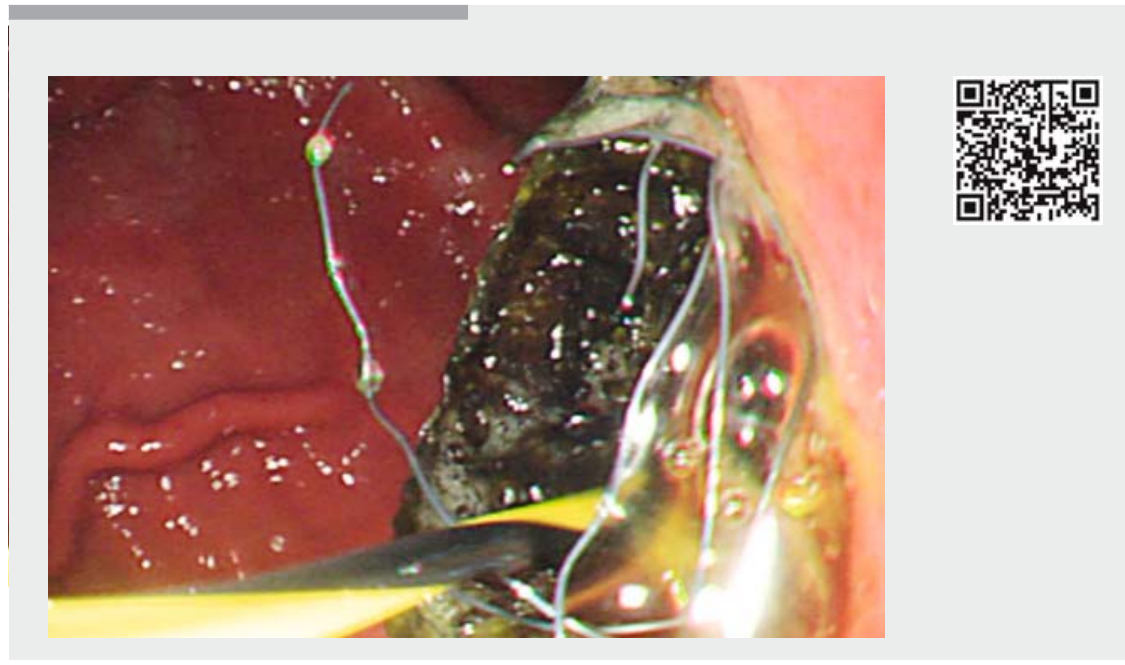

Video 1 Endoscopic exchange of a lumen-apposing metal stent after endoscopic ultrasound-guided gastroenterostomy in acute pancreatitis.

significantly 9 months later. The patient could no longer tolerate the nasogastric nutrition but strongly refused surgery. Ultimately, he accepted treatment with EUS-GE, performed according to the reported method [5], and could tolerate a semi-liquid oral diet after the procedure

\section{( $>$ Fig. 1, V Video 1).}

Unfortunately, the initial symptoms recurred and worsened 6 months later. UGI revealed no improvement in the duodenal obstruction. Gastroscopy found fractures in some of the steel wires of the stent ( Fig.2a). Gastroscopy and fluoroscopy showed that the inner diameter of the stent had decreased significantly ( $\triangleright$ Fig. $\mathbf{2 b}, \mathbf{c}$ ). The stent might have been ineffective due to corrosion by gastric juice. A new LAMS was deployed into the gastrojejunal anastomosis ( Video 1 ), and the patient resumed a semi-liquid diet after the procedure.

This case suggests that LAMS could be effective for about 6 months but needs to be exchanged periodically in patients requiring long-term treatment.

Endoscopy_UCTN_Code_TTT_1AS_2AG
[1] Khashab MA, Bukhari M, Baron TH et al. International multicenter comparative trial of endoscopic ultrasonography-guided gastroenterostomy versus surgical gastrojejunostomy for the treatment of malignant gastric outlet obstruction. Endosc Int Open 2017; 5: E275-E281

[2] Chen YI, James T, Agarwal A et al. EUS-guided gastroenterostomy in management of benign gastric outlet obstruction. Endosc Int Open 2018; 6: E363-E368

[3] Coronel E, Chapman CG, Matthews J et al. Endoscopic ultrasound-guided gastroenterostomy for the treatment of gastroduodenal obstruction in severe chronic pancreatitis. Endoscopy 2018; 50: 285-287

[4] Binmoeller KF, Shah JN. Endoscopic ultrasound-guided gastroenterostomy using novel tools designed for transluminal therapy: a porcine study. Endoscopy 2012; 44: $499-503$

[5] Itoi T, Ishii K, Ikeuchi $\mathrm{N}$ et al. Prospective evaluation of endoscopic ultrasonographyguided double-balloon-occluded gastrojejunostomy bypass (EPASS) for malignant gastric outlet obstruction. Gut 2016; 65: 193 195

The authors

Wei Wang, Ke Qi, Zhendong Jin, Zhaoshen Li Department of Gastroenterology, Changhai Hospital Affiliated to the Second Military Medical University, Shanghai, PR China

\section{Corresponding author}

\section{Zhendong Jin, MD}

Department of Gastroenterology, Changhai Hospital Affiliated to the Second Military Medical University, Building No. 11, Changhai Road No.168, Yangpu District, Shanghai 200433, PR China Fax: +86-21-31161336 jinzhendong2017@163.com

Endoscopy E-Videos is a free

\section{Bibliography}

DOI https://doi.org/10.1055/a-0756-6971

Published online: 7.11.2018

Endoscopy 2019; 51: E18-E19

(c) Georg Thieme Verlag KG

Stuttgart · New York

ISSN 0013-726X

\section{ENDOSCOPY E-VIDEOS}

https://eref.thieme.de/e-videos

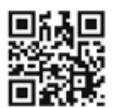
access online section, reporting on interesting cases and new techniques in gastroenterological endoscopy. All papers include a high quality video and all contributions are freely accessible online.

This section has its own submission website at https://mc.manuscriptcentral.com/e-videos 